\title{
Developmental expression of the Drosophila zeste gene and localization of zeste protein on polytene chromosomes
}

\author{
Vincenzo Pirrotta, Sharon Bickel, and Celestina Mariani ${ }^{1,2}$ \\ Department of Cell Biology, Baylor College of Medicine, Houston, Texas 77030 USA; \\ ${ }^{1}$ European Molecular Biology Laboratory, Heidelberg, Federal Republic of Germany
}

\begin{abstract}
The expression of the zeste gene varies through the life cycle of the fly. Its transcription is most abundant in maternal RNA, declines to very low levels during larval growth, but rises again in late third instar larvae and pupae. Using transposons containing a zeste-lacZ gene, we found a corresponding variation in the tissue distribution of zeste from stage to stage. Nearly ubiquitous expression of the zeste-lacZ gene is found in late embryos and first instar larvae, but disappears almost completely except in brain and gonads by third instar larva. Shortly before pupation expression rises again in imaginal discs, Malpighian tubules, and salivary glands and again becomes nearly ubiquitous in pupae. zeste continues to be expressed in adult brain and gonads. We constructed flies carrying a zeste gene controlled by the heat shock promoter and studied the distribution of zeste protein in their polytene chromosomes as well as those of wild-type flies. Using affinity-purified anti-zeste antibodies, we find that wild-type salivary gland chromosomes contain about 60 strong bands of zeste immunofluorescence at specific cytological locations. After heat induction of larvae containing the hs-zeste gene, many hundreds of bands appear. These results suggest the involvement of zeste in the expression of a wide variety of genes at different developmental stages.
\end{abstract}

[Key Words: Transvection; zeste; developmental regulation; immunofluorescence; polytene chromosomes]

Received May 23, 1988; revised version accepted October 3, 1988.

The zeste gene of Drosophila was identified genetically on the basis of two apparently distinct effects that it exercises on certain other genes. One of these is the ability to mediate transvection, the effect of regulatory elements of one copy of a target gene on the expression of a second copy of the gene on a homologously paired chromosome. Such transvection effects were first observed at the UItrabithorax $(U b x)$ gene by Lewis (1954), who showed that they were dependent on the activity of a gene later identified as zeste (Kaufman et al. 1972). zeste-dependent transvection effects since have been observed at two other loci, white and decapentaplegic (dpp) (Babu and Bhat 1980; Gelbart and Wu 1982). The second, perhaps more dramatic, effect of zeste is that produced by a particular zeste mutant, $z^{1}$, on the expression of the white gene. Gans (1953) found that in this mutant, the white gene is strongly repressed if it is present in two copies brought in close physical proximity by somatic chromosome pairing or by tandem duplication (Judd 1961; Green 1963). Bingham and Zachar (1985) showed that this effect was due to a strong suppression of transcription of the white gene in the eye, where it is re-

${ }^{2}$ Present address: Plant Genetic Systems, J. Plateaustraat 22, B9000 Gent, Belgium. quired for pigment deposition. The effect is eye specific and it is not observed in other tissues that have whitedependent pigmentation. These observations strongly suggest an interaction of zeste with control elements that govern the transcription of its target genes, but the genetic evidence has so far not revealed any requirement for zeste in normal gene expression. Mutations in the zeste gene that prevent transvection have no detectable effect on the functioning of wild-type $U b x$ or $d p p$ genes, although some of them may alter the expression of white.

The zeste gene has been cloned (Mariani et al. 1985; Gunaratne et al. 1986) and the sequences of the wild type and some of its mutants have been determined (Pirrotta et al. 1987; Mansukhani et al. 1988). Using zeste protein expressed in bacteria, Benson and Pirrotta (1987, 1988) have shown that the zeste product is a DNAbinding protein that recognizes specific sites in the white, $U b x$, and other genes. One of these sites at $U b x$ is in the immediate vicinity of the transcription start site (nucleotides -40 to -150 ). zeste protein bound to this site acts in vitro as a transcription factor stimulating the synthesis of $U b x$ RNA (Biggin et al. 1988). Evidence of this sort raises the question of whether zeste might have a more important role in gene expression, a role not substantially affected by any of the known zeste mutations. 
If these mutations only interfere with a higher-order zeste effect such as transvection, they would uncover only a small part of the involvement of zeste in gene expression. To assess the extent of this involvement, it is important therefore to determine when and where the zeste gene is expressed. Furthermore, the three genes known to give transvection effects appear to have very little in common. zeste may well interact also with other genes a knowledge of which may provide a better basis for understanding the role of zeste.

In this paper, we explore the activity of the zeste gene during development of the fly, its distribution in different tissues, and the localization of the zeste product on polytene chromosomes.

\section{Results}

\section{Developmental profile of zeste transcription}

The three genes that have given us genetic evidence of zeste function are all expressed at various stages from embryo to adult but, in particular, they are active in the late larva and early pupa. The phenotypes affected by zeste-dependent transvection effects are all visible in the adult as defects in imaginal disc derivatives. We do not know whether zeste is active at any other stage since no transvection effects have been reported on the embryonic phenotypes of $d p p$ or $U b x$ mutants. Gunaratne et al. (1986) have in fact found zeste mRNA expressed at earlier developmental stages. To examine the changes in activity of the zeste gene during development, we made poly $(\mathrm{A})^{+}$RNA preparations from all developmental stages, taken at 1-day intervals, and hybridized them to a zeste probe (Fig. 1). Surprisingly, the highest accumulation of zeste RNA was found in unfertilized eggs, corresponding therefore, to maternal RNA. zeste transcript

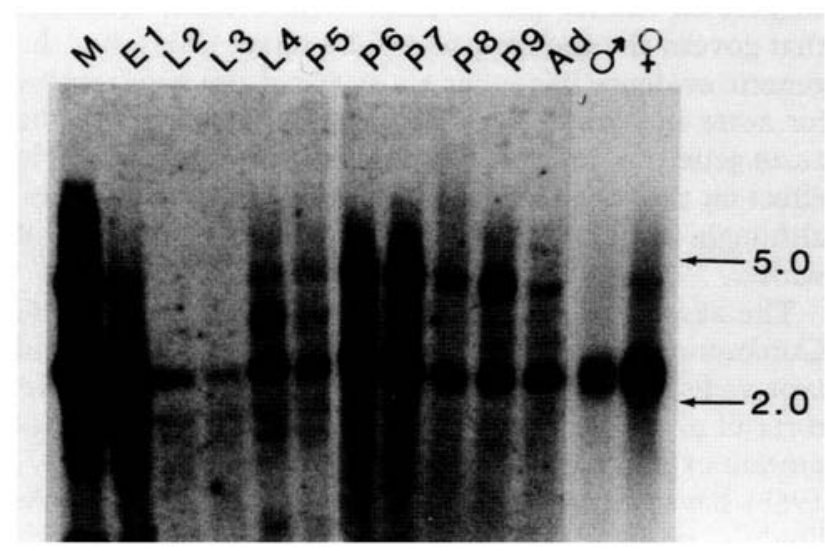

Figure 1. Northern blot hybridization to zeste RNA. Each lane contained $5 \mu \mathrm{g}$ of poly $(\mathrm{A})^{+}$RNA from different developmental stages except lane P8, which contained $2 \mu \mathrm{g}$. The blot was hybridized with a nick-translated probe containing the entire zeste gene. (Lane $M$ ) Maternal RNA; (lanes E1-P9) developmental stages at $24-\mathrm{hr}$ intervals at $25^{\circ} \mathrm{C}$; (lane $A d$ ) adult RNA; (lanes $\delta$ and $\$$ ) $m a l e$ and female adult RNAs. The zeste mRNA is the major band of $2.5 \mathrm{~kb}$. Arrows indicate the position of the 2- and 5-kb copia RNAs, determined on the same filter. decreases in abundance during embryonic development and reaches a minimum, but still detectable, level in first and second instar larvae. It climbs again in third instar larvae and reaches a second peak in the pupa. Moderate levels are still found in both male and female adults.

\section{zeste-lacZ fusions}

To examine in more detail the tissue and developmental distribution of zeste activity, we resorted to the use of the bacterial lacZ gene as a reporter. We had previously shown that a functional zeste gene was contained in a 3.9-kb BamHI fragment (Pirrotta et al. 1987). Therefore, we used a DNA fragment containing the zeste 5'flanking region starting from the BamHI site and including the promoter and the nucleotides encoding the first 49 amino acid residues of the zeste polypeptide. This was fused in-frame to a lac $Z$ fragment encoding an active $\beta$-galactosidase polypeptide. The construction was assembled in the pUChsneo vector for P-mediated germ line transformation (Steller and Pirrotta 1985a) and injected into embryos. Transformed lines, selected for their G418 resistance, were made homozygous and then examined for expression of the zeste- $\beta$-galactosidase gene at different developmental stages.

Despite the presence of abundant zeste RNA in unfertilized eggs, early embryos gave no detectable staining for $\beta$-galactosidase activity. Staining was first detected during germ band extension; it increased to a maximum around stage 16 of Campos-Ortega and Hartenstein (1985) in all tissues including the epidermis. Newly hatched larvae were still fairly uniformly stained, but the activity and its distribution continued to decrease during larval development (Fig. 2). In early third instar larvae, staining persisted only in the gonads, central nervous system, sections of the gut, and the tissues surrounding the head skeleton. As the larvae reached the climbing stage, a wider pattern of staining reappeared. Malpighian tubules, salivary glands, ring gland, and imaginal discs became progressively and sequentially stainable. By the beginning of pupation all these tissues were expressing the hybrid gene fully. During metamorphosis, this analysis was complicated by the higher levels of endogenous $\beta$-galactosidase that accumulate in the wild-type pupa. These could be reduced but not completely eliminated by performing the staining reaction at $\mathrm{pH} 8$. It was clear, however, that expression of the hybrid gene continued in all imaginal disc derivatives, as well as in the abdomen of the developing imago. The intensity and distribution of staining receded in the pharate adult but was still detectable in parts of the appendages, particularly the antennae and in the thoracic musculature. Continued expression was found in the adult brain and gonads. A very similar pattern of expression was found in three independent lines transformed with the same transposon.

Of particular interest was the appearance of staining in the salivary glands of late third instar larvae. The earliest signs of activity occurred in the distal, posterior end 
of the glands as accumulations of blue stain in the polytenic nuclei and especially at or near the nuclear membrane, suggesting that the zeste- $\beta$-galactosidase hybrid protein might partition preferentially in the nucleus. Later the entire gland acquired a blue color.

\section{Heat shock-zeste transposons}

The observation that the zeste- $\beta$-galactosidase gene was activated in the salivary glands of the third instar larva raised the possibility of detecting zeste protein on the salivary gland polytenic chromosomes. Because its normal levels of expression are rather low, we decided first to overexpress the zeste gene by transcribing its coding sequence from the $h s p 70$ promoter. To do this, we used a nearly full-length zeste cDNA, trimmed its untranslated leader sequence by cutting it at the KpnI site, removed about 25 bp with Bal31 exonuclease, and ligated it, together with a 456-bp fragment containing the $h s p 70$ promoter, into the pUChsneo vector /Steller and Pirrotta 1985a). The resulting transposon was injected into $z^{a}$ embryos, which produce a mutant zeste
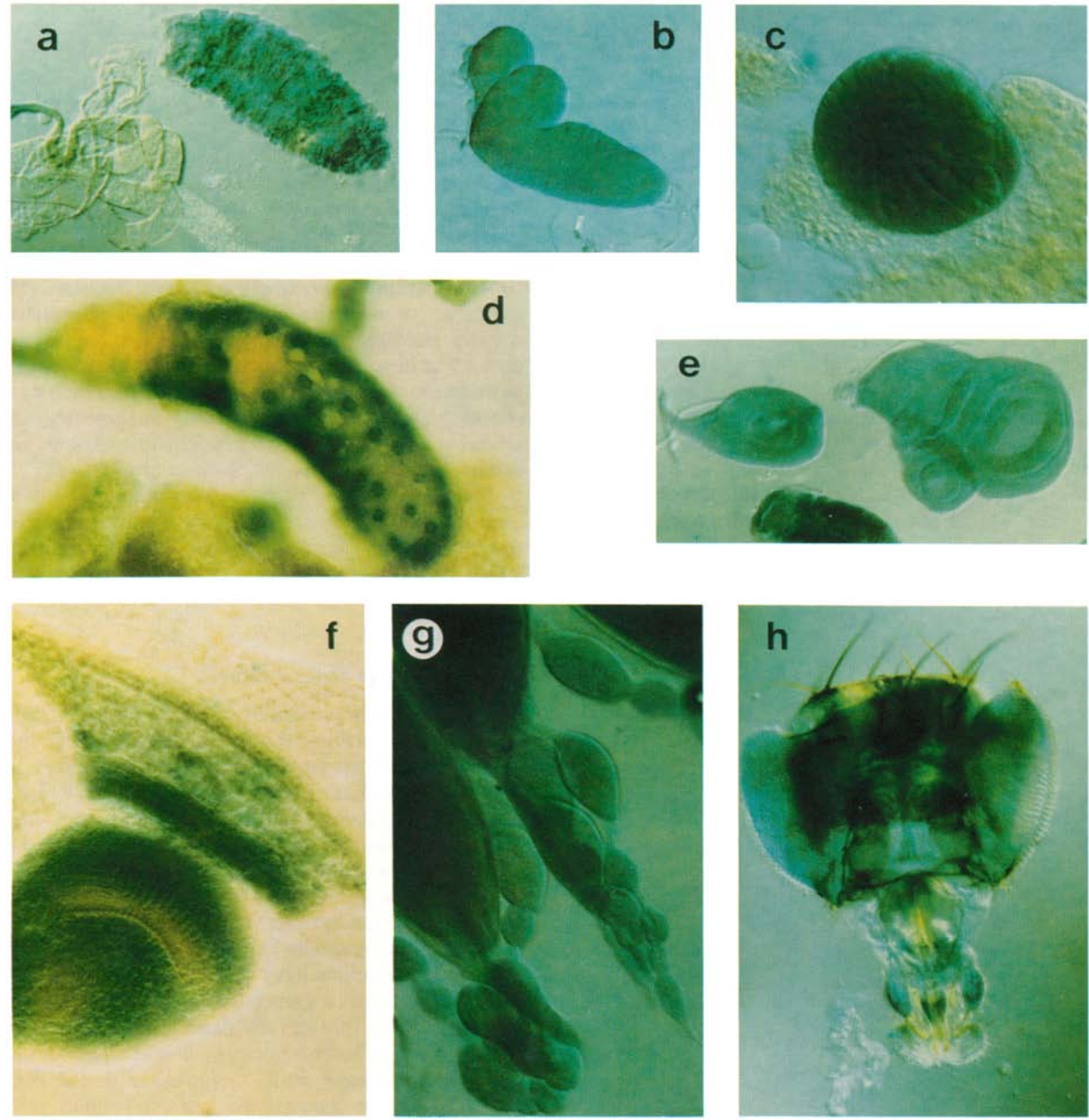

Figure 2. Expression of a zeste- $\beta$-galactosidase hybrid gene. Animals homozygous for a transposon containing the zeste gene fused in frame to the $l a c Z$ gene were dissected and stained for $\beta$-galactosidase activity. First instar larval cuticle $(a)$ and central nervous system $\langle b|$; late third instar larval testis $(c)$, salivary gland $\{d\rangle$, and imaginal discs $(e)$; early pupa optic lobe and eye $(f)$; adult ovaries $(g)$; and head $(h)$. The enlargement varies from case to case. 
product unable to complement the $z^{1}$ mutation. Transformed flies were detected by crossing the $G_{0}$ flies to $z^{1}$ mutant partners and selecting individuals able to survive G418 food. All surviving females were also red-eyed when raised at room temperature, indicating that a functional zeste gene was present and that the basal level of the heat shock promoter in the $h s-z e s t e$ gene sufficed to complement the $z^{1}$ mutant product. Two independent lines, $h s-z 2$ and $h s-z 3$, made homozygous for the hs$z e s t e$ transposon, were selected for further study.

To verify that the transformed flies actually produce higher levels of zeste protein after heat shock induction, we compared the amounts of protein detected on Western blots with or without heat treatment. We used an affinity-purified antiserum directed against the carboxy-terminal region of the zeste protein. As Figure 3 shows, fly extracts made after heat shock contain at least 10 times more immunoreactive zeste protein than extracts from wild-type flies with or without heat shock. In the absence of heat shock, the uninduced level of zeste protein in flies carrying the $h s-z e s t e$ transposon is still approximately two- or threefold higher than that found in wild-type flies.

We tested the ability of the hs-zeste gene to promote transvection at $U b x$ using the $C b x U b x /++$ configuration in a $z^{a}$ background (Gelbart and Wu 1982). In $C b x$ $U b x /++$ flies, zeste-dependent transvection causes the $C b x$ regulatory mutation on one chromosome to direct inappropriate expression of the wild-type gene copy on the other chromosome, resulting in a partial transformation of posterior wing to haltere. When such flies carrying one copy of the hs-zeste transposon in a $z^{a}$ background were raised at room temperature transvection effects were minimal. Stronger transvection phenotypes, but still substantially weaker than those observed in the presence of a normal zeste gene, were obtained by heatshocking the flies for $1 \mathrm{hr}$ daily during larval growth.

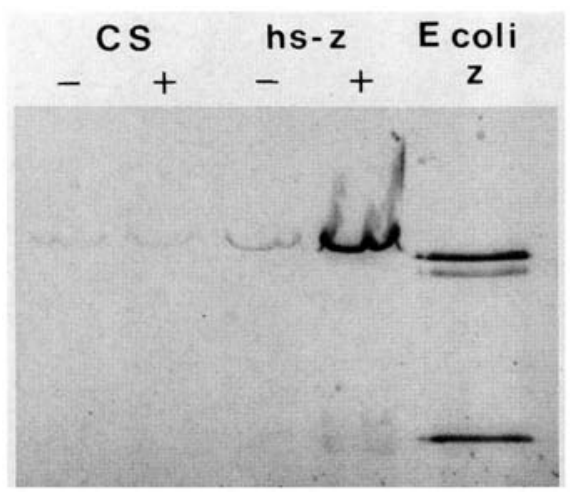

Figure 3. Western blot analysis of the hs-zeste gene expression. Nuclear extract equivalents of 50 flies were applied to each lane. zeste protein was detected after blotting with affinity-purified anti-zeste antibody. The two lanes on the left represent control Canton S flies without or with heat shock. The middle two lanes represent flies homozygous for the hszeste transposon, without and with heat shock. The lane on the right contains zeste protein expressed in E. coli.
Such short heat treatment regimes did not harm these flies appreciably and gave rise to no obvious abnormalities.

We tested the hs-z 2 line homozygous for the hs-zeste transposon on the second chromosome for the effects of heat shock in two ways. In the first experiment we collected staged embryos, mounted them on a slide, timed their arrival to the cellular blastoderm stage, and then heat-shocked them at $37^{\circ} \mathrm{C}$ for $15 \mathrm{~min}$. As a result, these embryos received a heat treatment at various stages between blastoderm and germ band extension. Their development was then monitored until hatching. We observed no lethality attributable to the heat shock nor any detectable segmental abnormality in the resulting first instar larvae. In the second experiment we prepared a series of vials by transferring the parental flies approximately every $12 \mathrm{hr}$. These vials, containing larvae at developmental stages ranging from first instar to pupae, were then heat-shocked at $37^{\circ} \mathrm{C}$ for $2.5 \mathrm{hr}$. After allowing development to continue, the vials were examined for pupal mortality or for the emergence of adults with abnormal phenotypes. By these criteria, heat treatment during larval development had no detectable effect until late third instar. Animals heat-shocked from this time on became increasingly sensitive, frequently dying as pupae or eclosing with generalized abnormalities usually affecting the wings or legs. The highest sensitivity was observed in animals that had just completed pupariation at the time of heat shock, in which case 16 out of 17 failed to eclose. Entirely analogously results were obtained with an independent line, hs-z 3, which carries the transposon on the third chromosome. Control wild-type flies in parallel experiments showed minimal effects. In the $h s-z$ lines, the chromosome bearing the transposon is derived from the $z^{a}$ stock originally injected. Heat treatment of the $z^{a}$ flies at the same stage resulted in a mortality rate of only $5 \%$ (7 of 144).

\section{In situ detection of zeste protein}

To visualize zeste protein in salivary gland cells we first used animals carrying the $h s-z e s t e$ gene under the assumption that this would maximize the chances of detection. Third instar larvae were placed at $37^{\circ} \mathrm{C}$ for $1 \mathrm{hr}$ and allowed to recover for another hour at room temperature before dissecting and fixing the salivary glands. Figure 4 shows cells and chromosome spreads stained by indirect immunofluorescence using an affinity-purified antibody directed against the carboxy-terminal quarter of the zeste polypeptide. Under these conditions, the cytoplasm is not appreciably stained but the nuclei show intense fluorescence associated with the chromosomes. In chromosome spreads, the fluorescence is distributed clearly in a very large number of discrete bands found in all the chromosome arms. Comparison of the fluorescence and phase-contrast photographs makes it clear that the fluorescence bands do not correspond to the normal chromomeric banding pattern. We note the following: (1) Bands of fluorescence are found preferentially in interband regions or at least in regions devoid of 

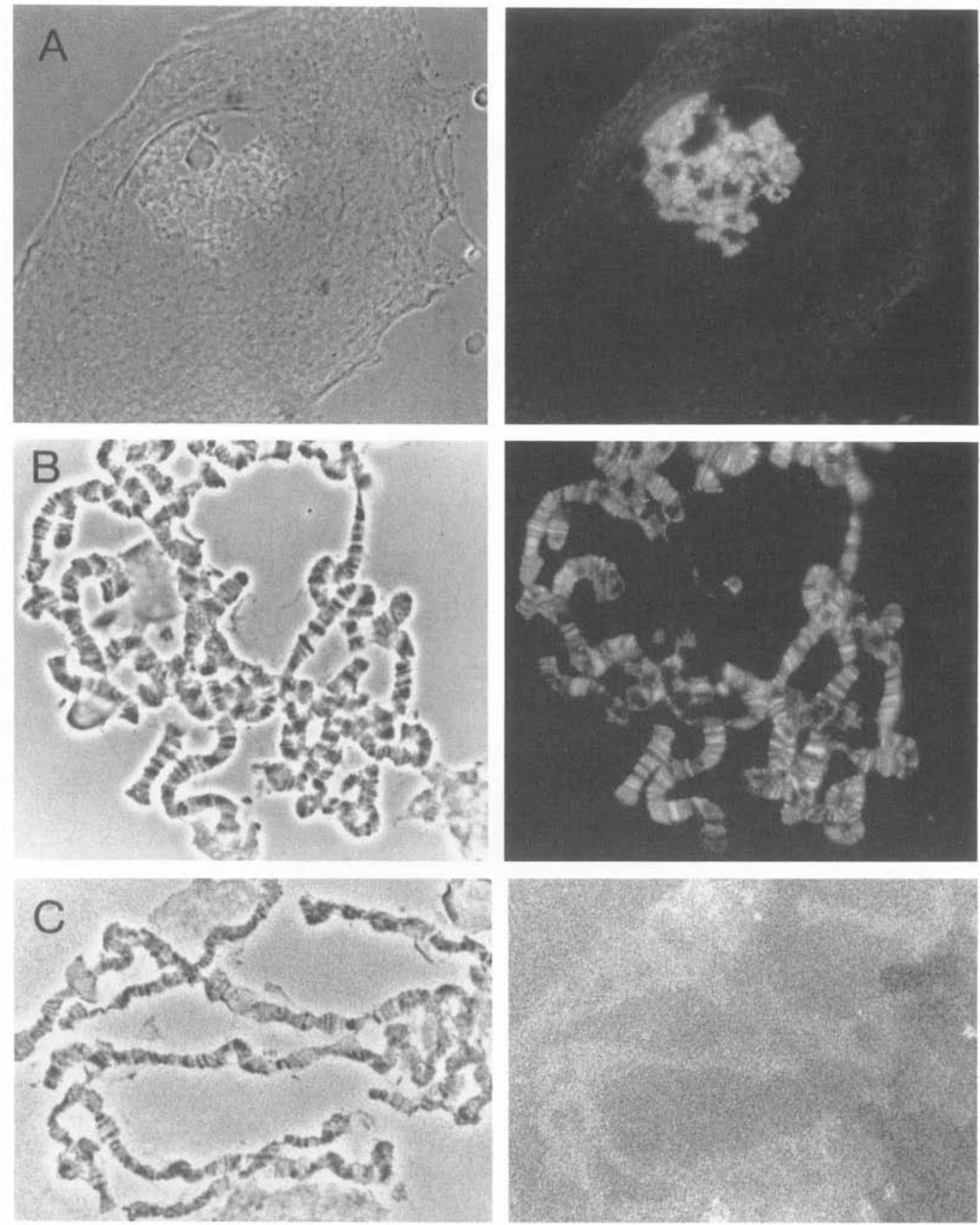

Figure 4. zeste immunofluorescence. In each case the panel on the left shows the phase-contrast picture, and the panel on the right, the immunofluorescence. $(A)$ Salivary gland from larvae homozygous for the hs-zeste transposon, after heat shock. $(B)$ Chromosome squash from cells such as in $A$. $(C)$ Chromosome squash from salivary glands of $\operatorname{In}(1) e(b x)$ larvae; the panel on the right is overexposed greatly here to show the absence of fluorescence.

strong bands under phase-contrast optics. (2) Not all interband regions fluoresce. (3) The chromocenter does not stain or only very faintly. (4) No staining is found in the nucleolus except possibly very faintly at its edges. (5) Non-heat-shocked larvae lack this massive immunofluorescence as do wild-type larvae that have been heatshocked.

Reassured of our capacity to detect zeste on the polytene chromosomes, we then investigated the pattern of fluorescence attributable to the endogenous zeste gene in wild-type salivary gland chromosomes. Figure 5 shows representative chromosome spreads and individual chromosomes. Bands of immunofluorescence are still detectable but in much lower numbers, distributed in all chromosome arms in a highly characteristic and reproducible pattern that is not affected appreciably by heat shock treatment. Approximately 60 strong or medium strong immunofluorescing sites can be counted, as 

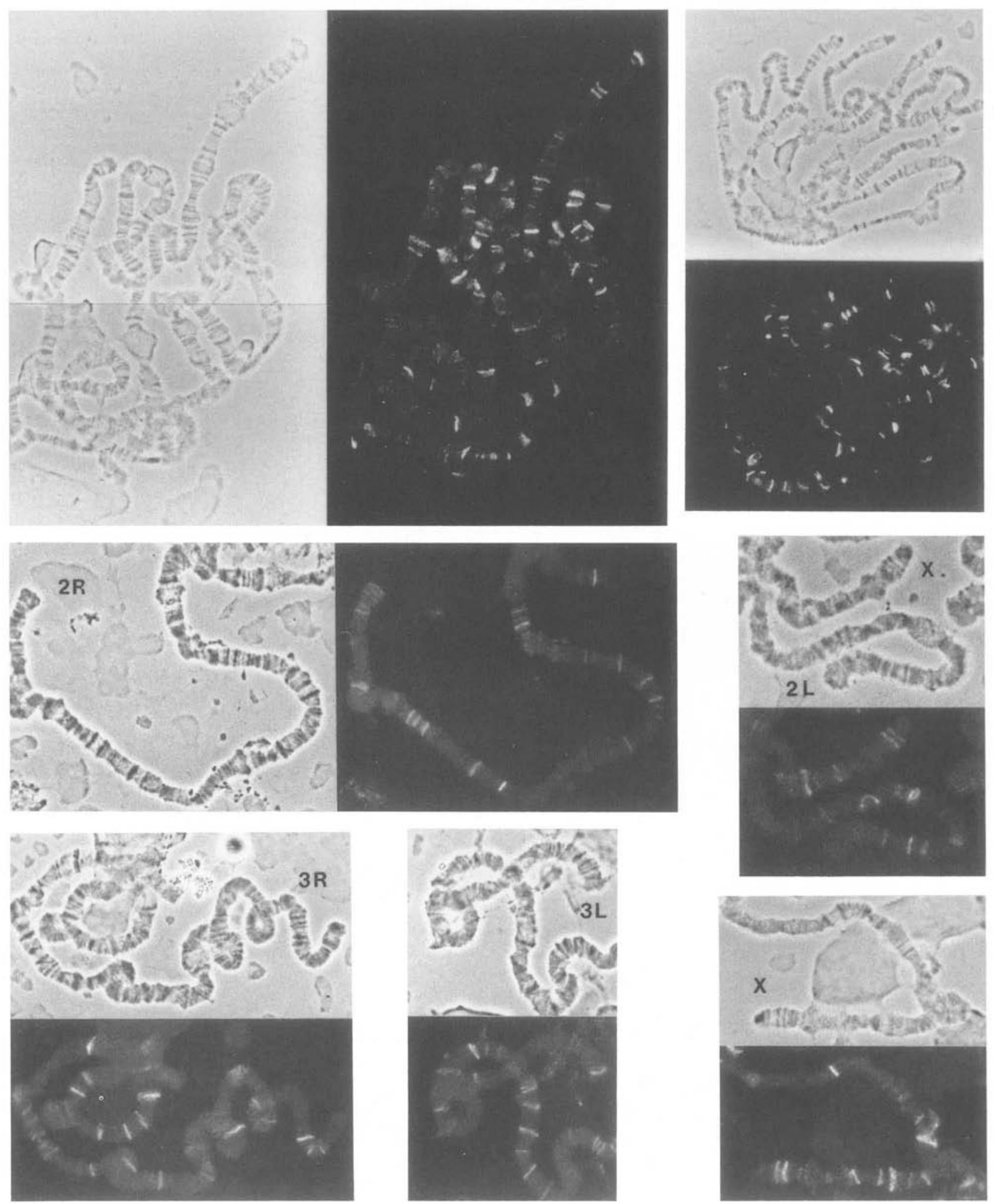

Figure 5. zeste immunofluorescence. Salivary gland chromosome squashes from wild-type larvae. The distal parts of individual chromosomes are shown. 
before, associated not with phase-contrast bands but rather with interbands or regions containing only faint bands. Puffs are conspicuously devoid of immunofluorescence but several chromosome regions give a very faint, punctate background instead of bands. Occasionally, bands of immunofluorescence are associated with chromosome sites involved in ectopic bridges but this is not a regular association because many more ectopic threads do not fluoresce.

In comparison with the wild type, the chromosomes of non-heat-shocked larvae carrying the hs-zeste gene in addition to a normal, endogenous copy of zeste give the impression of having a somewhat higher number of immunofluorescent bands (Fig. 6). A detailed comparison between the two shows that the actual pattern of bands is approximately the same but the overall intensity is higher in the hs-zeste case, allowing normally weakly fluorescing sites to appear relatively strong. However, some new bands not visible in wild-type flies, clearly do appear in these chromosomes; for example, note a third band near the tip of the $\mathrm{X}$ chromosome at $1 \mathrm{~F}-2 \mathrm{~A}$ in addition to the two normally present at $1 \mathrm{C}$ and $\mathrm{ID}$ (Fig. 7).

The effect of heat shock on the immunofluorescence observed with the hs-zeste larvae makes it clear that our antibody is truly detecting zeste protein. As an additional control, to ensure that it is not detecting anything other than zeste protein, we used chromosome spreads prepared from the $\operatorname{In}(1) e(b x)$ strain. In these flies, the zeste gene is split by an inversion breakpoint approximately in the middle of the coding region (Pirrotta et al. 1987). The resulting gene would make a polypeptide lacking the carboxy-terminal half of the zeste protein and therefore unable to react with the antibody. Figure 4C shows that these chromosomes, treated with the carboxy-terminal antibody exactly in parallel with wild-type chromosomes, fail to exhibit any appreciable immunofluorescence. An examination of the chromosomes from $z^{1}$ mutant larvae showed that they immunofluoresce, as far as could be determined, in the same pattern and to a similar extent as the wild type.

Given the reproducibility of the banding pattern detected by the antibody, we next attempted to attribute some of the bands to loci known to interact with zeste, that is, white, $d p p$, and $U b x$. In brief, a faint band of fluorescence was detectable at approximately $89 \mathrm{E}$, the cytological location of the bithorax complex, and a distinct band was present at $22 \mathrm{~F}$, the approximate site of $d p p$. That this fluorescence corresponds to the $U b x$ and $d p p$ loci cannot, of course, be established from these experiments. In contrast, no appreciable fluorescence could be detected at $3 \mathrm{Cl}, 2$ where the white gene is known to reside (Fig. 8). Although this site is flanked by strong bands of fluorescence, $3 \mathrm{Cl}, 2$ itself remains clearly unlabeled. Interestingly, the neighboring bands
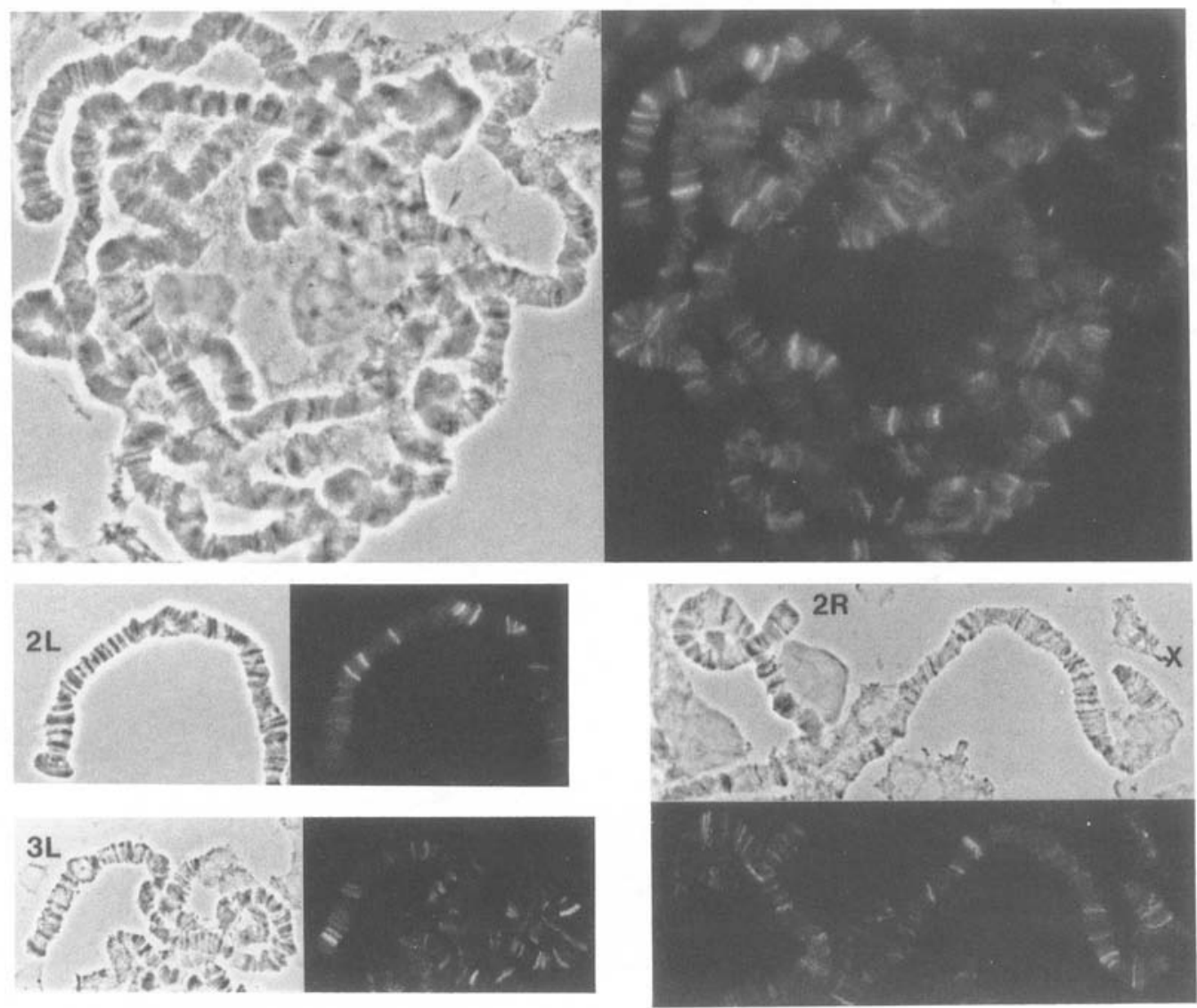

Figure 6. zeste immunofluorescence. Salivary gland chromosome squashes from larvae homozygous for the hs-zeste transposon with no heat shock. Note the appearance of bands that were weak or undetectable in corresponding chromosomal sites in Fig. 5 . 


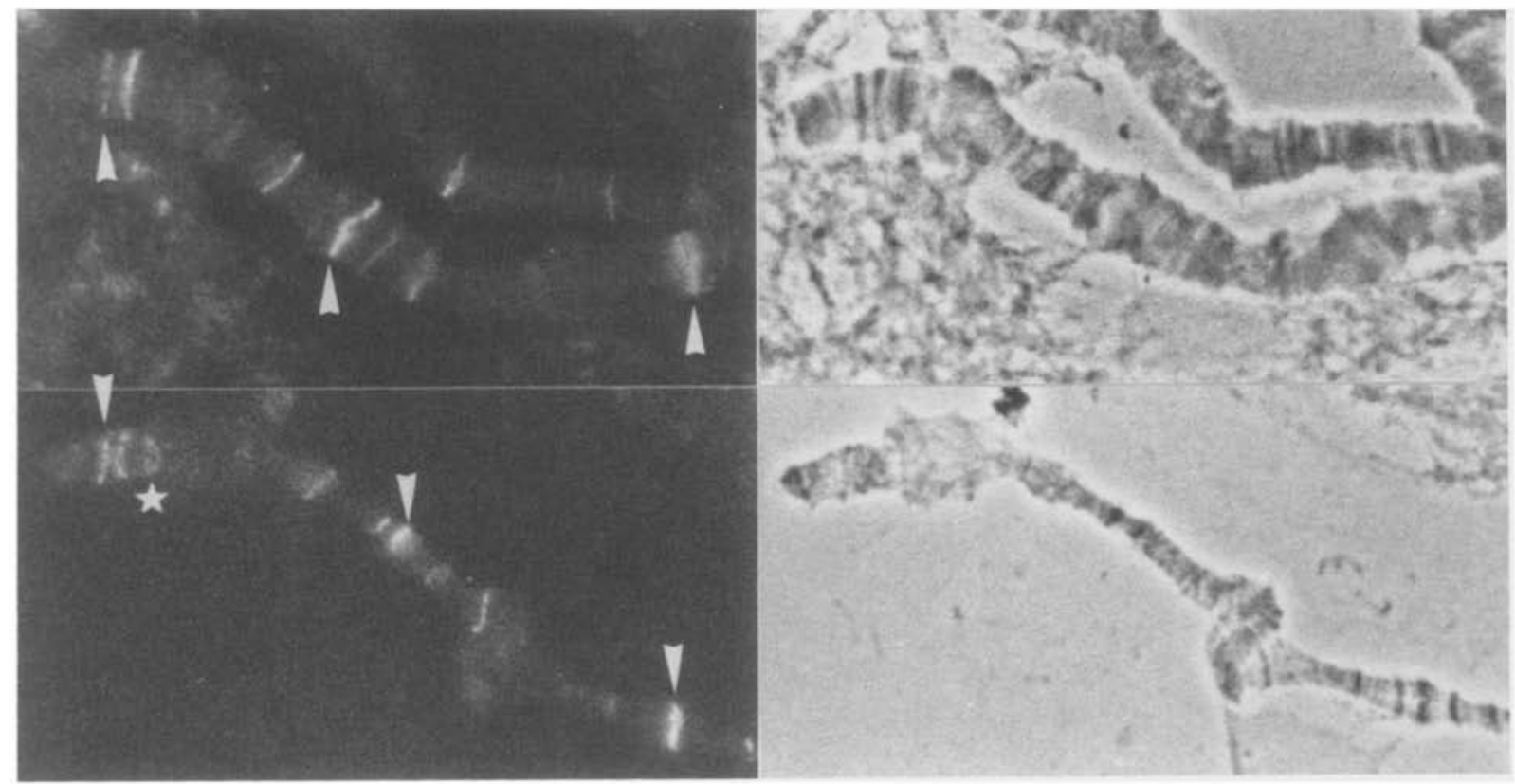

Figure 7. Reproducibility of zeste banding pattern. The banding pattern is highly reproducible in chromosomes from larvae at the same stage (white prepupae). This is illustrated by comparing the wild-type distal X chromosome shown here (upper panel) with the X chromosomes in Figs. 5 and 6 and with the $\mathrm{X}$ chromosome from non-heat-shocked larvae carrying the hs-zeste transposon (lower panel). In these larvae, containing two- to threefold more zeste, immunofluorescence is stronger and one new band appears at $1 \mathrm{~F}-2 \mathrm{E}$ (marked by a star), which is not detected in the wild type. The arrowheads serve to align corresponding bands.

of fluorescence correspond as nearly as can be determined to 3D3,4 (strong band), to 3C11,12 (weaker band), the site of the sgs-4 gene, and to $3 \mathrm{~A} 3$, the site of the zeste gene itself.

Finally, we examined the salivary gland chromosomes of another Drosophila species, $D$. virilis, believed to have diverged from the branch that evolved into $D$. melanogaster about 45 million years ago (Beverley and Wilson 1984). Figure 9 shows that our antibody detects zeste-like bands in $D$. virilis salivary gland chromosomes but fewer in number and, with two or three exceptions, much lower in intensity than those observed in D. melanogaster.

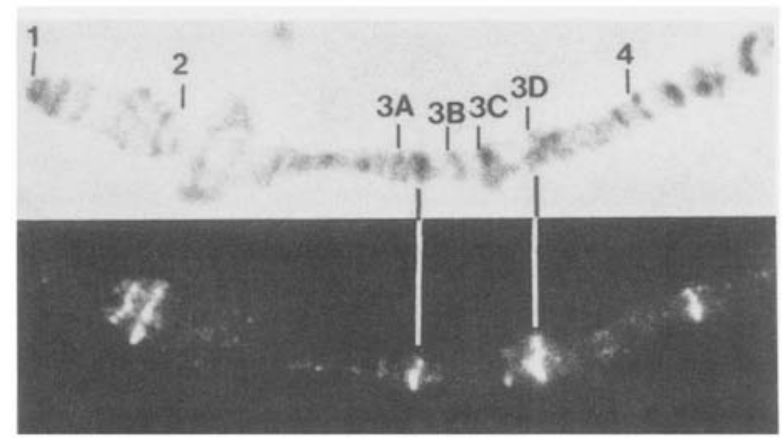

Figure 8. zeste immunofluorescence near the tip of the $\mathrm{X}$ chromosome. Although fluorescent bands are present at 3A2-3, $3 \mathrm{Cl} 1-12$, and $3 \mathrm{D} 3-4$, no band is visible at $3 \mathrm{C} 1-2$, the site of the white gene.

\section{Discussion}

In contrast to the known genetic effects involving zeste, which are so far limited to three loci and to phenotypes affecting imaginal derivatives, the results reported here indicate that zeste mRNA is present throughout development but principally in the embryo. After virtually disappearing in early larval stages, a second, strong peak of transcription occurs in the late third instar larvae and early pupa. This is confirmed by the experiments using zeste-lacZ hybrid gene. Surprisingly, despite the abundance of zeste mRNA in unfertilized embryos and the expression of the zeste-lac $Z$ gene in ovaries, the early embryo does not stain for $\beta$-galactosidase activity until the extended germ band stage, suggesting some mechanism of translation control. Staining activity, which declines in the early larval stages, revives in intensity and distribution shortly before pupation and becomes nearly ubiquitous in the pupa. In contrast to the genetic data, these results indicate a much more widespread activity of the zeste gene in a large variety of tissues and developmental stages. In particular, they suggest the involvement of zeste in the expression of embryonic genes.

\section{Effects of zeste overexpression}

The hs-zeste construction was made with two basic purposes in mind. One was to overexpress the gene to produce higher amounts of zeste protein for biochemical and cytological studies and the other was to determine whether abnormally high levels of zeste in inappropriate tissues or developmental stages had deleterious effects 


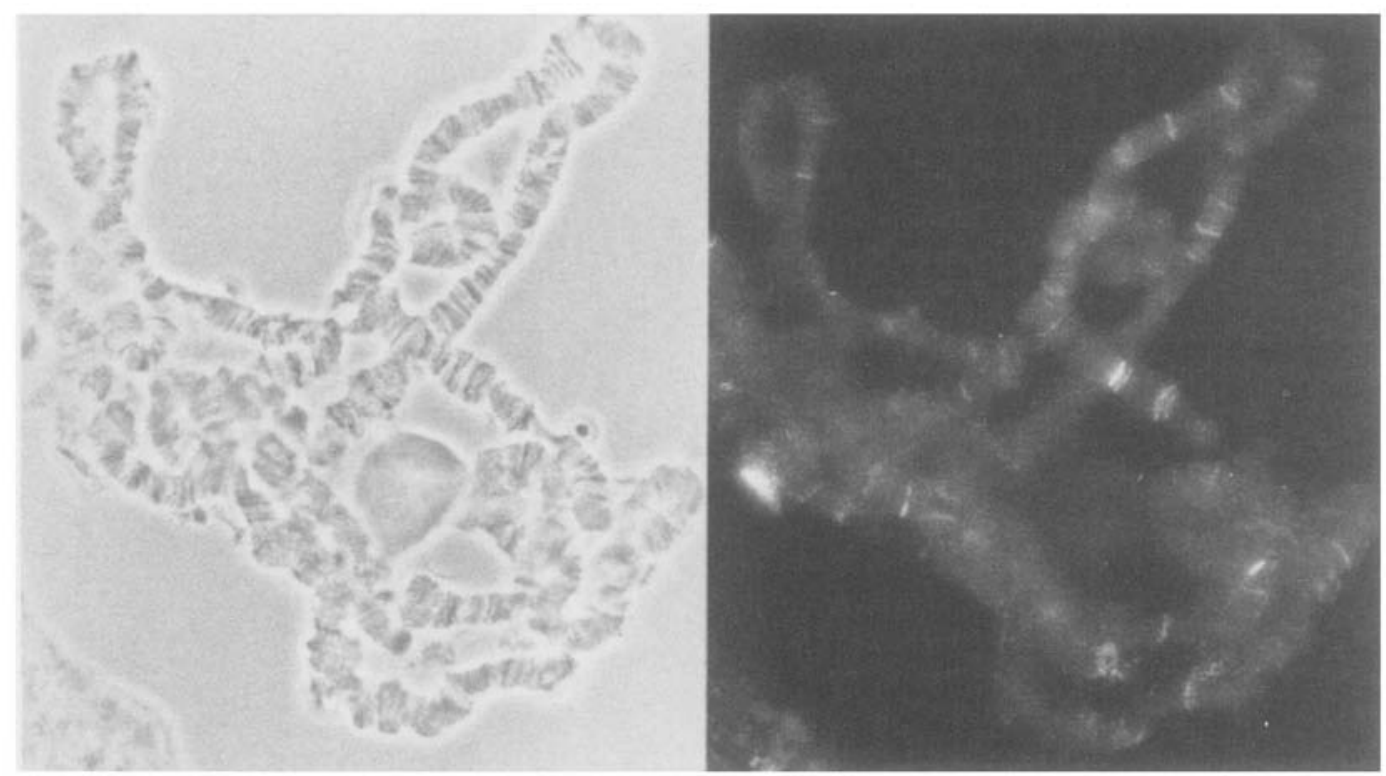

Figure 9. zeste immunofluorescence in salivary gland chromosome squashes from Drosophila virilis. Note that although the photograph was overexposed, the fluorescence is much weaker than in the D. melanogaster chromosomes.

on gene expression. With respect to the second question, activation of the hs-zeste gene at early embryonic stages caused no detectable lethality or segmental abnormalities. On the other hand, heat shocks administered to late third instar larvae or early pupae resulted in abnormalities and widespread pupal lethality in two different lines carrying the transposon on different chromosomes. It is unlikely that this heat sensitivity is caused by some preexisting mutation in the parent $z^{a}$ strain, since the $z^{a}$ flies have a much lower rate of pupal mortality. Furthermore, repeated backcrosses for both transformed lines have replaced all the chromosomes except for the one carrying the transposon. Therefore, it is likely that zeste overexpression in the late larva-early pupa has deleterious effects, possibly causing overexpression of some target genes. This would not be surprising in view of the effect of zeste on transcriptional activation in vitro (Biggin et al. 1988) and in tissue culture cells (P. Miller and V. Pirrotta, unpubl.). What is puzzling is that zeste overexpression did not appear to affect earlier stages. A possible explanation is that, at these stages, zeste is not the limiting factor governing the expression of critical genes like $U b x$ and $d p p$. Their transcription might depend on other factors present in limiting amounts or it might be suppressed by negative regulators.

The basal level of expression of the heat shock promoter at room temperature is adequate to provide enough zeste product to complement two endogenous copies of zeste gene carrying the $z^{1}$ mutation. This leakiness of the $h s p 70$ promoter, previously observed in the case of hs-white (Steller and Pirrotta 1985b) and of hs-P transposase gene (Steller and Pirrotta 1986) confirms the conclusion reached from the levels of zeste mRNA that the normal amounts of zeste protein present in cells (or at least in the eye disc) are rather low. The basal level of the $h s-z e s t e$ gene is not adequate to promote transvection effects in a $z^{a}$ background. When the level of expression was boosted by the administration of short heat shocks during larval development, transvection effects became visible though less pronounced than those caused by an endogenous zeste gene or by a transposon carrying a wild-type zeste gene. A possible explanation for this result might be that higher or sustained local levels of zeste are required for transvection effects. The zeste protein produced after a pulse of activation might have a short half-life and thus be insufficient over a more extended time period, while later heat shocks cause pupal lethality.

\section{zeste on polytene chromosomes}

Larvae carrying the hs-zeste gene show clearly a massive increase in zeste product after heat shock, as detected by Western blots or by immunofluorescence. As far as can be detected in salivary gland cells, the immunofluoresence is associated exclusively with the nucleus and specifically with the polytenic chromosomes. Even after heat shock-induced overproduction, zeste is found only on the chromosomes, in a pattern of discrete bands not corresponding to bands of higher DNA concentration, indicating that it is associated with specific regions. In wild-type chromosomes, zeste is detected at about 60 sites. This is consistent with our previous observation that zeste protein binds in vitro to specific DNA sequences from the white and $U b x$ genes (Benson and Pirrotta 1987) and argues against a role of zeste as a generalized glue holding together homologous chromosomes. The vastly greater number of bands observed when zeste is overproduced suggests that at higher concentrations zeste can occupy lower affinity sites or, possibly, that under these conditions, it is able to displace 
other proteins blocking access to many more potential binding sites.

Needless to say, we have no evidence that the presence of zeste protein at many or all of the chromosomal sites is functional or necessary. It could be fortuitous. Nevertheless, the number of sites in salivary gland chromosomes and the wide distribution of zeste activity indicated by the zeste-lac $Z$ fusion gene, suggest that zeste can interact potentially with a wide range of genes. At least some of the genes correspond to complex, developmentally important loci such as $U b \mathrm{x}$ and $d p p$, as intimated by the genetic results, as well as engrailed or Antennapedia, as shown by in vitro binding studies (Benson and Pirrotta 1988). The immunofluorescence observations indicate that zeste is not found in transcriptionally inactive regions of the chromosomes, such as the chromocenter or highly condensed bands, but rather in interband regions or at least in regions that do not contain strong Bridges bands. Experiments using incorporation of $\left[{ }^{3} \mathrm{H}\right]$ uridine or immunolocalization of RNA polymerase II have shown that it is in such decondensed regions that transcriptional activity is found in salivary gland chromosomes (Jamrich et al. 1977; Semeshin et al. 1979). Clearly, however, not all transcriptionally active regions give zeste immunofluorescence in our experiments. In particular, even strong puffs show no detectable presence of zeste.

While it is possible that bands of immunofluorescence are associated with the $d p p$ and $U b x$ loci, which we know interact with zeste from both genetics and in vitro binding studies (Gelbart and Wu 1982; Benson and Pirrotta 1987, 1988), we have not detected zeste protein at the white locus. Using calibrated, fluorescein-labeled beads, we estimated that about 1000 fluorescein molecules $/ \mu \mathrm{m}^{2}$ would be detected easily over a dark background. A squashed chromosome is $2-4 \mu \mathrm{m}$ wide and a band is $\sim 0.2-\mu \mathrm{m}$ thick. Assuming that each binding sequence becomes labeled with one fluorochrome, with a level of polyteny of 1000 a single binding site would be easily visible. However, we do not know the efficiency of antibody binding to chromosome squashes, the number of zeste polypeptides associated with each binding site, or the number of antibody molecules able to bind to each zeste molecule. The white gene is not known to be active in the salivary glands. Therefore, it is possible that the accessibility of potential zeste binding sites is correlated with gene activity. Preliminary observations suggest in fact that changes in the pattern of immunofluorescing bands can be detected between younger third instar larvae and prepupae. An alternative explanation is that detection of zeste is much less efficient than our estimate and that the chromosomal sites revealed by immunofluorescence are sites of exceptional affinity or able to bind an unusual number of zeste molecules. We can rule out this possibility at least in the case of the band of immunofluorescence at $3 \mathrm{~A}$ on the $\mathrm{X}$ chromosome. Clones representing a $220-\mathrm{kb}$ chromosomal walk covering the $3 \mathrm{~A}$ region (Mariani et al. 1985) were tested for zeste binding sites in vitro. Only a small number of zeste binding sites of intermediate strength were observed, fewer and weaker than those found at the white or $U b x$ loci. Comparison of the immunofluorescence obtained with two deletion mutants allowed the localization of the fluorescing site to an $8-\mathrm{kb}$ interval containing the zeste gene itself, raising the possibility that zeste is autoregulating /S. Qian and V. Pirrotta, unpubl.). The band of fluorescence detected near 3C11-12 is also of interest because it is at or near the cytological locus of $s g s-4$. This gene is active in third instar larvae, and transvection effects between some of its alleles have been reported (Korge 1981; Kornher and Brutlag 1986), although they have not been shown to be dependent on zeste.

Although our experiments localize zeste on the chromosomes, they leave unresolved the question of its possible association with other nuclear structures such as the nuclear envelope. It has been suggested, for example, that zeste might anchor certain chromosomal regions to nuclear structures where the transcriptional machinery resides (Pirrotta et al. 1985; Zachar et al. 1985). Because the chromosomes are so enormously hypertrophied in polytenic nuclei, they are likely to dwarf and obscure most other nuclear structures. Unless other possible zeste binding structures are magnified to a similar degree, their contribution to zeste immunofluorescence therefore is not likely to be detected.

\section{zeste mutants}

The pattern of fluorescence detected in salivary gland chromosomes of the $z^{1}$ mutant did not differ appreciably from the wild type, and, in particular, no new band of fluorescence appeared over the white locus. This is in agreement with previous observations that indicated that this mutation does not cause overexpression of the gene (Mariani et al. 1985), that the mutant gene contains a single codon change near the carboxyl terminal of the molecule (Pirrotta et al. 1987), and that the mutant protein has the same DNA-binding properties as the wildtype protein (S. Bickel and V. Pirrotta, unpubl.). The lack of immunofluorescence observed with the $\operatorname{In}(1) e(b x)$ mutant confirms the conclusion that the antigen detected in wild-type flies is the product of the zeste gene. The $\operatorname{In}(1) e(b x)$ mutant has a inversion breakpoint in the middle of the protein coding region which removes the $3^{\prime}$ half of the gene. Hence, its product would not be recognized by our antibody which is directed to the carboxy-terminal portion of the protein. We have shown (S. Bickel and V. Pirrotta, unpubl.) that a zeste mutant produced in vitro, deleted at approximately the same position, produces a protein that is still able to bind specifically to DNA and may have at least part of the zeste functions, although it cannot be detected by the antibody directed to the carboxy-terminal region.

\section{Materials and methods}

Fly strains and mutants

Oregon R (Heidelberg) flies were used as a source of RNA for the developmental Northern blots. zeste mutants used in this 
work were y $z^{a}$, obtained from Gif-sur-Yvette and carrying an apparent point mutation in the zeste gene unable to complement $z^{1}$ or to support transvection and $\operatorname{In}(1) e(b x)$, containing a small inversion with a breakpoint in the middle of the zeste coding region (Pirrotta et al. 1987), obtained from E. Lewis. Transvection effects were tested using $C b x U b \times g 1^{3 / T}(2,3)$ $a p^{X a}$, obtained from C.-T. Wu. The $D$. virilis stock was kindly provided by A. Spradling.

\section{Northern blot hybridization}

RNA was isolated from unfertilized embryos or from embryos, larvae, pupae, and adults staged at 1-day intervals. The RNA was extracted as described by Pirrotta et al. (1983) and the poly $(\mathrm{A})+$ component was isolated by two cycles of binding and elution from a poly(U) Sepharose column in buffer containing $10 \mathrm{~mm}$ Tris (pH 7.5), $10 \mathrm{~mm}$ EDTA, $0.2 \%$ SDS, and $0.2 \mathrm{M} \mathrm{NaCl}$. The column was eluted with $10 \mathrm{~mm}$ Tris $(\mathrm{pH} 7.5), 10 \mathrm{~mm}$ EDTA, and $50 \%$ formamide. The RNA was analyzed on agarose-formaldehyde gels (Maniatis et al. 1982), blotted on a nitrocellulose filter, and hybridized in $50 \%$ formamide, $10 \times$ Denhardt's solution, $100 \mu \mathrm{m} / \mathrm{ml}$ denatured calf thymus DNA, and $2 \times \mathrm{SCC}$ at $43^{\circ} \mathrm{C}$. After hybridization the filter was washed in $2 \times \mathrm{SCC}$ and then in $0.2 \times \mathrm{SSC}$ at $65^{\circ} \mathrm{C}$.

\section{Construction of transposons and P-mediated transformation}

Transposons were constructed in the pUChsneo vector (Steller and Pirrotta 1985a). The zeste-lacZ gene was assembled using the zeste upstream sequence from the BamHI site to the PvuII site at position 1050 (Pirrotta et al. 1987) and ligating it in phase to a lacZ gene bearing the SV40 polyadenylation site constructed by C. Thummel and D. Hogness. The hs-zeste gene was assembled with the same hsp 70 promoter fragment used previously (Steller and Pirrotta 1985a) ligated to a nearly fulllength zeste cDNA trimmed to reduce the leader sequence to $\sim 120$ nucleotides before the translation start. The transposons were injected into early embryos at a concentration of 400 $\mu \mathrm{g} / \mathrm{ml}$ together with $80 \mu \mathrm{g} / \mathrm{ml}$ of the helper phs $\pi$ plasmid (Steller and Pirrotta 1986). $G_{2}$ progeny were selected by growth on instant food 4-24 (Carolina Biological Supply Co.) containing $800 \mu \mathrm{g} / \mathrm{ml} \mathrm{G418}$ (Geneticin, Sigma).

\section{In situ detection of $\beta$-galactosidase}

The procedure was adapted from that of Glaser et al. (1986). Larvae and pupae of adults were dissected in Insect Ringer's solution, and then fixed for $15 \mathrm{~min}$ in $2 \%$ glutaraldehyde in 50 $\mathrm{mM}$ sodium cacodylate ( $\mathrm{pH} 7.5$ ). The dissected animals were washed twice with either citrate-phosphate buffer $[0.2 \mathrm{M}$ $\mathrm{Na}_{2} \mathrm{HPO}_{4}, 0.003 \mathrm{M}$ citric acid $\left.(\mathrm{pH} 8.2)\right]$ or buffer A [10 mM sodium phosphate $\{\mathrm{pH} 7.0\}, 150 \mathrm{mM} \mathrm{NaCl}, 1 \mathrm{~mm} \mathrm{MgCl}{ }_{2}$ ] (Glaser et al. 1986) and then stained with the same buffer containing 3 $\mathrm{mM} \mathrm{K} \mathrm{K}_{3} \mathrm{Fe}(\mathrm{CN})_{6}$ and $3 \mathrm{mM} \mathrm{K}{ }_{4} \mathrm{Fe}(\mathrm{CN})_{6} \cdot 3 \mathrm{H}_{2} \mathrm{O}$ and $0.2 \%$ 5-bromo4-chloro 3-indolyl- $\beta$-D-galactopyranoside (X-Gal). Incubation in the staining solution generally was allowed to continue for $8-14 \mathrm{hr}$. At the lower $\mathrm{pH}$ (buffer A), staining was more vigorous but endogenous activity was also higher, particularly in the pupa. At the higher $\mathrm{pH}$, the endogenous activity was suppressed almost entirely at the cost of longer incubation and paler color development. The dissected organs were mounted on slides in $30 \%$ glycerol and $70 \%$ ethanol and photographed with Kodachrome 64.

\section{Affinity purification of zeste antibody}

$\beta$-Galactosidase or a $\beta$-galactosidase fusion protein containing the last 105 amino acids from the carboxy-terminal of the zeste protein made in Escherichia coli (Benson and Pirrotta 1987) were electroeluted from preparative acrylamide gels and coupled to cyanogen bromide-activated Sepharose 4B (Pharmacia) at a concentration of $1.3-1.5 \mathrm{mg} / \mathrm{ml}$ of resin. After coupling, the columns were equilibrated with buffer containing $100 \mathrm{mM}$ $\mathrm{H}_{3} \mathrm{BO}_{3}, 25 \mathrm{~mm}$ sodium borate, $75 \mathrm{~mm} \mathrm{NaCl}$ (pH 8.4). Serum from immunized rabbits $(30 \mathrm{ml})$ was first depleted of anti- $\beta$-galactosidase antibodies by passing it three times through the $\beta$ galactosidase column. The flowthrough was applied to the zeste- $\beta$-galactosidase column. After washing, specifically bound antibodies were eluted using $200 \mathrm{~mm}$ glycine, $0.8 \%$ $\mathrm{NaCl}(\mathrm{pH} 2.7)$. Fractions of $0.5 \mathrm{ml}$ were collected and neutralized immediately with $25 \mu \mathrm{l} 2 \mathrm{M}$ Trizma base. Peak fractions were pooled, dialyzed against PBS buffer ( $\mathrm{pH} 7.4)$, aliquoted, and frozen at $-70^{\circ} \mathrm{C}$.

\section{Western blotting}

One hundred flies $(\sim 0.1$ gram $)$ were either left at room temperature or heat-shocked $1 \mathrm{hr}$ at $37^{\circ} \mathrm{C}$ followed by $1 \mathrm{hr}$ recovery at room temperature. Each set was homogenized in $1 \mathrm{ml}$ of buffer containing $0.15 \mathrm{M} \mathrm{NaCl}, 0.01 \mathrm{M}$ Tris $(\mathrm{pH} 8), 5 \mathrm{~mm}$ EDTA, $0.2 \%$ NP-40, $2 \mathrm{mM}$ phenyl methylsulfonylfluoride (PMSF) in a $7-\mathrm{ml}$ Dounce homogenizer with an 'A' pestle. The homogenate was filtered through glass wool, layered on a two-layer sucrose cushion composed of $1 \mathrm{ml}$ of $1.6 \mathrm{M}$ sucrose and $1 \mathrm{ml}$ of $0.8 \mathrm{M}$ sucrose and centrifuged for $20 \mathrm{~min}$ at $10,000 \mathrm{rpm}$ in a JA-20 rotor at $4^{\circ} \mathrm{C}$. Lipid material adhering to the walls was wiped off and the nuclear pellets were resuspended in $8 \mathrm{M}$ urea, $100 \mathrm{~mm}$ Tris $(\mathrm{pH} 7.6), 2 \%$ SDS, $5 \% \beta$-mercaptoethanol, $5 \%$ Ficoll and sonicated extensively. Nuclear extract corresponding to 50 flies was loaded in each lane of a $7.5 \%$ acrylamide-SDS gel (Dreyfuss et al. 1984). The gel was electroblotted onto a nitrocellulose filter using a Sartorius semidry electroblotter. The filter was blocked using $3 \%$ milk solids in TBS [10 mM Tris (pH 7.4), $0.9 \% \mathrm{NaCl}$ ] and then incubated for $1 \mathrm{hr}$ at room temperature in affinity-purified antibody solution $10.8 \mu \mathrm{g} / \mathrm{ml}$ in TBS plus milk solids). After washing, alkaline phosphatase-conjugated antirabbit IgG (Promega Biotec) was added at a $1: 7500$ dilution in TBS plus milk solids. The blot was developed using the Promega AP substrate kit.

\section{Immunofluorescence on polytene chromosomes}

The procedure used is derived partly from that of Silver and Elgin (1976) and partly from Jamrich et al. (1977). Late third instar larvae and prepupae were dissected in Insect Ringer's solution and the salivary glands were transferred to a drop of PBS buffer containing $3.6 \%$ formaldehyde for $45 \mathrm{sec}$ on a subbed slide. Lengthening the prefixing time or shortening it to $5 \mathrm{sec}$ did not affect the results appreciably, except that with longer prefixing times the chromosomes become increasingly more difficult to spread. The glands were then transferred to a drop of $45 \%$ acetic acid, $3.6 \%$ formaldehyde and the chromosomes were spread under a siliconized cover slip by gently rotating the cover slip with the tip of a dissecting needle. After squashing, the slide was dipped in liquid nitrogen and the cover slip was flicked off with a razor blade. The slide was then washed in $95 \%$ ethanol for $1-24 \mathrm{hr}$, then in PBS for $1 \mathrm{hr}$. The squash was rinsed briefly with PBS containing $10 \%$ goat serum before shaking off the excess liquid and applying the affinity-purified antiserum at $3.3 \mu \mathrm{g} / \mathrm{ml}$ in $30 \mu \mathrm{l}$ of the same buffer. After incubating for $30 \mathrm{~min}$ at room temperature under a cover slip in a humidified petri dish, the slide was rinsed and allowed to wash for $30 \mathrm{~min}$ in PBS. FITC-conjugated goat anti-rabbit second antibody (Cappel) that had been preadsorbed by incubating with permeabilized, formaldehyde-fixed Drosophila embryos was 
then applied at a $1: 200$ dilution in PBS and allowed to incubate for $30 \mathrm{~min}$. The slides were then washed $30 \mathrm{~min}$ in PBS and mounted under a cover slip in $50 \%$ glycerol containing $1 \times$ PBS $(\mathrm{pH} 8.8)$ and $10 \mathrm{mg} / \mathrm{ml} p$-phenylenediamine to retard photobleaching. Bleaching was also decreased by sealing the edges of the cover slip with nail polish to exclude oxygen. For extra sharp photomicrographic images, some of the squashes were prepared on $24 \times 60-\mathrm{nm}$ coverslips instead of normal microscope slides. In this case, after the antibody treatments the cover slip bearing the chromosomes was cut with a diamond pencil and mounted upside down on a cover slip. The chromosomes were viewed under epifluorescence and phase-contrast optics in a Zeiss Axiophot and photographed with Kodak Tri-X film.

\section{Acknowledgments}

We thank Joe Bryan and Sean Carroll for advice, Carl Thummel for the lacZ cassette, and Ting Wu for fly stocks. We are grateful to Elaine McGuffin for expert assistance and to Kelly Bevans for preparing the manuscript. C.M. and S.B. were the recipients of European Molecular Biology Laboratory and $\mathrm{Na}$ tional Science Foundation predoctoral fellowships, respectively. The research was supported by National Institutes of Health grant GM-34630 to V.P.

\section{References}

Babu, P. and S.G. Bhat. 1980. Effects of zeste on white complementation. In Development and neurobiology of Drosophila (ed. O. Siddiqi P. Babu, L.M. Hall, and J.C. Hall), pp. 35-38. Plenum Press, New York.

Benson, M. and V. Pirrotta. 1987. The product of the Drosophila zeste gene binds to specific DNA sequences in white and Ubx. EMBO I. 6: 1387-1392.

- 1988. The Drosophila zeste protein binds cooperatively to sites in many gene regulatory regions: Implications for transvection and gene regulation. EMBO $\mathrm{f}$. (in press).

Beverley, S.M. and A.C. Wilson. 1984. Molecular evolution in Drosophila and the higher Diptera II. A time scale for fly evolution. J. Mol. Biol. 21: 1-13.

Biggin, M.D., S. Bickel, M. Benson, V. Pirrotta, and R. Tijan. 1988. zeste encodes a sequence specific transcription factor that activates the Ultrabithorax promoter in vitro. Cell 53: 713-722.

Bingham, P.M. and Z. Zachar. 1985. Evidence that two mutations wDZL and $z^{1}$ affecting synapsis-dependent genetic behavior of white are transcriptional regulatory mutations. Cell 40: 819-829.

Campos-Ortega, J.A. and V. Hartenstein. 1985. The embryonic development of Drosophila melanogaster. Springer-Verlag, Berlin.

Dreyfuss, F., S.A. Adam, and Y.D. Choi. 1984. Physical change in cytoplasmic messenger ribonucleoproteins in cells treated with inhibitors of mRNA transcription. Mol. Cell. Biol. 4: 415-423.

Gans, M. 1953. Etude genetique et physiologique du mutant $z$ de Drosophila melanogaster. Bull. Biol. Fr. Belg. (suppl.) 38: $1-90$.

Gelbart, W.M. and C.-T. Wu. 1982. Interactions of zeste mutations with loci exhibiting transvection effects in Drosophila melanogaster. Genetics 102: 179-189.

Glaser, R.L., M.F. Wolfner, and J.T. Lis. 1986. Spatial and temporal pattern of hsp26 expression during normal development. $E M B O ~ I .5: 747-754$.
Green, M.M. 1963. Unequal crossing over and the genetical organization of the white locus of Drosophila melanogaster. Z. Vererbungs1. 94: 200-214.

Gunaratne, P.H., A. Mansukhani, S.E. Lipari, H.-C. Liou, D.W. Martindale, and M.L. Goldberg. 1986. Molecular cloning, germline transformation and transcriptional analysis of the zeste locus of Drosophila melanogaster. Proc. NatI. Acad. Sci. 83: 701-705.

Jamrich, M., A. Greenleaf, and E.K.F. Bautz. 1977. Localisation of RNA polymerase in polytene chromosomes of Drosophila melanogaster. Proc. Nat1. Acad. Sci. 74: 2079-2083.

Judd, B.H. 1961. Formation of duplication-deficiency products by asymmetrical exchange within a complex locus. Proc. Natl. Acad. Sci. 47: 545-550.

Kaufman, T.C., S.E. Tasaka, and D.T. Suzuki. 1972. The interaction of two complex loci zeste and bithorax in Drosophila melanogaster. Genetics 75: 299-321.

Korge, G. 1981. Genetic analysis of the larval secretion gene sgs-4 and its regulatory chromosome sites in Drosophila melanogaster. Chromosoma 84: 373-390.

Kornher, J.S. and D. Brutlag. 1986. Proximity-dependent enhancement of $s g s-4$ gene expression in $D$. melanogaster. Cell 44: 879-883.

Lewis, E.B. 1954. The theory and application of a new method of detecting chromosomal rearrangements in Drosophila melanogaster. Am. Nat. 88: 225-239.

Maniatis, T., E.F. Fritsch, and J. Sambrook. 1982. Molecular cloning: A laboratory manual. Cold Spring Harbor Laboratory, Cold Spring Harbor, New York.

Mansukhani, A., P.H. Gunaratne, P.W. Sherwood, B.J. Sneath, and M.L. Goldberg. 1988. Nucleotide sequence and structural analysis of the zeste locus of Drosophila melanogaster. Mol. Gen. Genet. 211: 121-128.

Mariani, C., V. Pirrotta, and E. Manet. 1985. Isolation and characterization of the zeste locus of Drosophila melanogaster. $E M B O$ I. 4: 2045-2052.

Pirrotta, V., C. Hadfield, and G.H.J. Pretorius. 1983. Microdissection and cloning of the white locus and the $3 \mathrm{~B} 1-3 \mathrm{C} 2$ region of the Drosophila X chromosome. EMBO I. 2:927934.

Pirrotta, V., H. Steller, and M.P. Bozzetti. 1985. Multiple upstream regulatory elements control the expression of the Drosophila white gene. EMBO I. 4: 3501-3508.

Pirrotta, V., E. Manet, E. Hardon, S.E. Bickel, and M. Benson. 1987. Structure and sequence of the Drosophila zeste gene. EMBO \%. 6: 791-799.

Semeshin, V.F., I.F. Zhimulev, and E.S. Belyaeva. 1979. Electron microscope autoradiographic study on transcriptional activity of Drosophila melanogaster polytene chromosomes. Chromosoma 73: 163-177.

Silver, L.M. and S.C.R. Elgin. 1976. A method for determination of the in situ distribution of chromosomal proteins. Proc. Nat1. Acad. Sci. 73: 423-427.

Steller, H. and V. Pirrotta. 1985a. A transposable P vector that confers selectable G418 resistance to Drosophila larvae. EMBO f. 4: 167-171.

- 1985b. Expression of the Drosophila white gene under the control of the hsp70 heat shock promoter. EMBO $\%$ 4: 3765-3772.

1986. P transposon controlled by the heat shock promoter. Mol. Cell. Biol. 6: 1640-1649.

Zachar, Z., C.H. Chapman, and P.M. Bingham. 1985. On the molecular basis of transvection effects and the regulation of transcription. Cold Spring Harbor Symp. Quant. Biol. 50: $337-346$. 


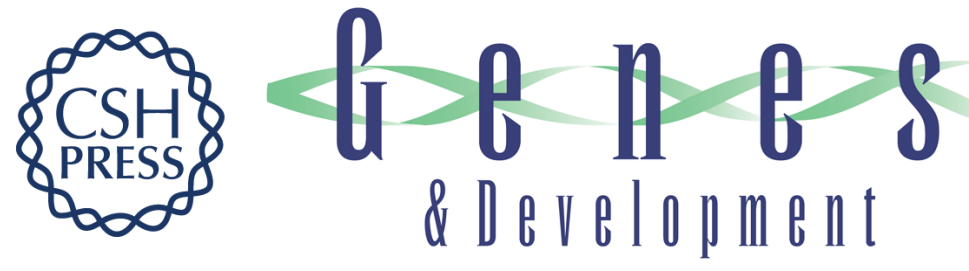

\section{Developmental expression of the Drosophila zeste gene and localization of zeste protein on polytene chromosomes.}

V Pirrotta, S Bickel and C Mariani

Genes Dev. 1988, 2:

Access the most recent version at doi:10.1101/gad.2.12b.1839

References This article cites 27 articles, 8 of which can be accessed free at:

http://genesdev.cshlp.org/content/2/12b/1839.full.html\#ref-list-1

License

Email Alerting

Service

Receive free email alerts when new articles cite this article - sign up in the box at the top right corner of the article or click here.

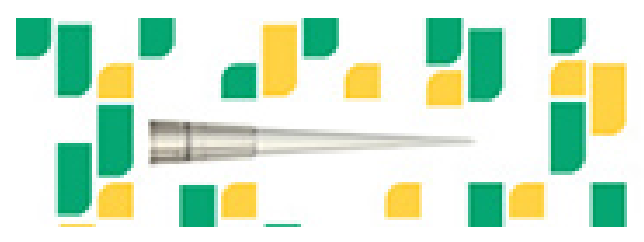

Focused on your science. 